\title{
Gum Arabic Solution
}

National Cancer Institute

\section{Source}

National Cancer Institute. Gum Arabic Solution. NCI Thesaurus. Code C155887.

A solution containing the polymer gum acacia (gum Arabic), exuded from various Acacia trees, especially from Acacia senegal (Leguminosae), with potential protective and antimucositis activities. Upon administration of the gum Arabic solution in the oral cavity, the polymer forms a protective barrier over the oral mucosa, which may prevent inflammation of the mucosal membranes and may decrease chemotherapy- and/or radiation-induced oral mucositis. 